\title{
0328 PATTERNS OF SEVERE WORK-RELATED INJURIES IN TANZANIA: CALL FOR NEW APPROACH TO WORKERS PROTECTION IN DEVELOPING COUNTRIES
}

Y M Kishashu*, A Franzblau, TRobins, G Smith Correspondence: Muhimbili University of Health and Allied Sciences, United Nations Road, PO Box 65015, Dar es Salaam, TZ, United Republic of Tanzania

\subsection{6/ip.2010.029215.328}

Background Work-related injuries affect people in their most productive years. Globally more than 5500 workers are killed by injuries and illnesses every day, and more than 270 million workers are injured at work each year (ILO, 2009). Severe work-related injuries and the resulting adverse socioeconomic impacts, represent a special burden to developing countries. This study, which was conducted in Tanzania, sought to describe patterns of severe traumatic work-related injuries; identify their causes and risk factors; evaluate the quality of reporting work-related injuries and; identify strategies for their prevention and control in Tanzania and other developing countries.

Methods Data was collected through structured interviews with 1385 injury cases admitted in the largest trauma hospital in Tanzania from March 2007 to March 2008. Detailed information was collected after work-relatedness of a case was established. Information from interviews was linked with hospital records, workers compensation and police data.

Findings A total of 638 (46\%) injury cases were classified as work-related injuries, and majority were male-workers (93\%). Linkage identified 138 (10\%) cases that were initially not identified as work-related. Peak age-group for both sexes was 2635 years. Road traffic injury was the most common reason for admission (62\%) followed by falls (15\%). Road was the leading place of injury (64\%) followed by work premises (27\%).

Conclusions The study revealed new patterns of work-related injuries in Tanzania. Road traffic safety becomes an important component of workers safety in Tanzania and other developing countries.

\section{Reference}

International Labor Organization (ILO). Facts Book 2009. ILO Publications, Geneva, 2009. 